\title{
Utilização do plasma rico em plaquetas autólogo nas cirurgias de enxertos cutâneos em feridas crônicas
}

\section{Use of autologous platelet-rich plasma in skin grafts surgeries in chronic wounds}

Fabiel Spani Vendramin ${ }^{1}$

Diogo FRANCO ${ }^{2}$

TAlita Romero Franco ${ }^{3}$

Trabalho realizado na Universidade Federal do Rio de Janeiro (UFRJ), Rio de Janeiro,

RJ, Brasil, com apoio do Hospital Central da Polícia Militar do Estado do Rio de Janeiro e da Santa Casa de Misericórdia do Pará, Belém, PA, Brasil .

Artigo submetido pelo SGP (Sistema de Gestão de Publicações) da RBCP.

Artigo recebido: 28/8/2010 Artigo aceito: 5/11/2010

\begin{abstract}
RESUMO
Introdução: O plasma rico em plaquetas (PRP) é um produto que estimula a cicatrização e pode ajudar na integração de enxertos cutâneos em feridas crônicas. Neste estudo, objetivou-se avaliar os resultados da aplicação do PRP nas cirurgias de enxerto de pele em feridas crônicas. Método: Foi realizado um estudo prospectivo randomizado e cego, em relação ao avaliador, da utilização do PRP nas enxertias cutâneas em feridas crônicas. Alocaram-se os pacientes em dois grupos: grupo A (controle), que recebeu enxerto de pele, sem PRP, e grupo B, que recebeu enxerto de pele e em parte da ferida foi utilizado o PRP, enquanto a outra parte serviu de comparação. Resultados: Houve melhor integração dos enxertos no lado que recebeu o PRP $\left(88,99 \%\right.$ no $14^{\circ} \mathrm{DPO}$ e $89,81 \%$ no $\left.28^{\circ} \mathrm{DPO}\right)$ do que no lado da mesma ferida, mas sem o PRP $\left(78,22 \%\right.$ no $14^{\circ} \mathrm{DPO}$ e $76,83 \%$ no $\left.28^{\circ} \mathrm{DPO}\right)$. No grupo A, a integração foi menor ( $77,85 \%$ no $14^{\circ} \mathrm{DPO}$ e $53,45 \%$ no $\left.28^{\circ} \mathrm{DPO}\right)$. O lado que recebeu o PRP evoluiu de forma mais favorável que o grupo A ( $\mathrm{p}$-valor $=0,0004)$ e houve menos perda total do enxerto no grupo $\mathrm{B}$ em comparação ao grupo $\mathrm{A}$ ( $\mathrm{p}$-valor $=0,049$ ). Conclusões: A aplicação do PRP nas feridas crônicas melhora a integração e a evolução dos enxertos de pele e diminui a incidência de perda total dos mesmos.
\end{abstract}

Descritores: Plasma rico em plaquetas. Transplante de pele. Cicatrização de feridas.

\begin{abstract}
Background: The platelet-rich plasma (PRP) is a product that improves the healing and can help integrate the grafts in chronic wounds. This study aimed to evaluate the results of application of PRP in surgery for skin grafting in chronic wounds. Method: We conducted a prospective study, randomized and blinded, in relation to the appraiser, to the use of PRP in skin grafting in chronic wounds. Patients were divided into two groups: group A (control), who received a skin graft, without the use of PRP, and group B, who received a skin graft and the wound was partly used PRP, while the other part served for comparison. Results: There was better graft integration on the side that used the PRP $\left(88.99 \%\right.$ in $14^{\text {th }}$ POD and $89.81 \%$ at 28 th POD) than the same side of the wound, without PRP (integration was $78.22 \%$ in $14^{\text {th }} \mathrm{POD}$ and $76.83 \%$ at $28^{\text {th }} \mathrm{POD}$ ). In group A, the integration was even lower $\left(77.85 \%\right.$ in $14^{\text {th }}$ POD and $53.45 \%$ on the $28^{\text {th }}$ POD). The side that used the PRP has evolved more favorably than group A $(\mathrm{p}$-value $=0.0004)$ and there was less total loss of the graft in group B than in group A (p-value $=0.049)$. Conclusions: The application of PRP in chronic wounds at the time of surgery, improve the integration and evolution of skin grafts and reduces the incidence of total loss.
\end{abstract}

Keywords: Platelet-rich plasma. Skin transplantation. Wound healing.

1. Doutor em Cirurgia Plástica pela UFRJ; Professor Adjunto de Técnica Cirúrgica e Cirurgia Experimental da UFPA; Cirurgião Plástico do Hospital Metropolitano de Urgência e Emergência; Belém, PA, Brasil. Membro Titular da Sociedade Brasileira de Cirurgia Plástica.

2. Doutor em Cirurgia Plástica pela UFRJ; Professor Adjunto de Cirurgia Plástica da UFRJ; Rio de Janeiro, RJ, Brasil. Membro Titular da Sociedade Brasileira de Cirurgia Plástica.

3. Doutora em Medicina; Professora Titular de Cirurgia Plástica da UFRJ; Rio de Janeiro, RJ, Brasil. Membro Titular da Sociedade Brasileira de Cirurgia Plástica. Membro da Academia Nacional de Medicina. 


\section{INTRODUÇÃO}

É frequente a necessidade de enxertos de pele para o tratamento das feridas crônicas e os resultados são muitas vezes frustrantes para o cirurgião, devido à alta incidência de perda parcial do enxerto e recidiva do ferimento.

Alguns trabalhos demonstraram redução dos fatores de crescimento (FC) nas feridas crônicas, tanto por diminuição na produção, quanto por diminuição na liberação, sequestro, excesso de degradação ou por combinação destes mecanismos $^{1-5}$. A análise do sobrenadante das feridas crônicas, comparado ao das feridas agudas, revelou diminuição dos fatores de crescimento ${ }^{1}$. Em úlceras crônicas, por um lado, ocorre uma rápida metabolização dos $\mathrm{FC}$ devido a proteinases presentes na ferida, de origem bacteriana ou celular ${ }^{4}$. Por outro lado, nas úlceras diabéticas e por insuficiência venosa, a diminuição dos fatores de crescimento ocorre devido a um mecanismo de sequestro pela fibrina que cerca os capilares ${ }^{3}$.

Podemos utilizar o plasma rico em plaquetas (PRP) para repor os $\mathrm{FC}$ e estimular a cicatrização dos enxertos. Em estudo anterior, demonstramos o benefício do PRP na integração de enxertos de pele em coelhos, o que incentivou seu uso em enxertos de pele em humanos ${ }^{6}$. Pelo fato de ser autólogo, não existe contraindicação para sua utilização. Seu preparo, apesar de não ser tão simples como postulado em alguns artigos e conferências, pode ser feito por um técnico treinado ${ }^{7,8}$.

Neste estudo, pretendemos avaliar a integração e a evolução dos enxertos de pele em feridas crônicas com a utilização do PRP.

\section{MÉTODO}

Esta pesquisa foi aprovada pelo Comitê de Ética em Pesquisa do Hospital Universitário Clementino Fraga Filho (UFRJ) e registrado na Comissão Nacional de Ética em Pesquisa (protocolo de pesquisa 024/05).

Foi realizado um estudo prospectivo randomizado e cego, em relação ao avaliador, da utilização do PRP nas enxertias cutâneas em feridas crônicas (feridas com mais de 3 meses de evolução). Quarenta e dois pacientes compuseram os grupos. Estes pacientes foram operados pelo mesmo cirurgião (primeiro autor do trabalho) no Hospital Universitário Clementino Fraga Filho (UFRJ), no Hospital da Polícia Militar do Estado do Rio de Janeiro e na Fundação da Santa Casa de Misericórdia do Pará.

O critério de inclusão foi paciente com ferida crônica com indicação de tratamento com enxerto de pele. Os critérios de exclusão foram: feridas infectadas, feridas com tecido necrosado e feridas em áreas tumorais.

Os pacientes foram alocados da seguinte forma:

- Grupo A - 11 pacientes; 11 feridas; receberam enxerto de pele, sem o uso do PRP.

- Grupo B-28 pacientes; 31 feridas; receberam enxerto de pele e, em parte da ferida, foi utilizado o PRP injetado sob ela.

No grupo B, as feridas foram divididas em duas partes, sendo consideradas partes direita e esquerda, ou cefálica e podálica, para avaliação da integração dos enxertos de pele. O PRP foi aplicado somente em uma parte da ferida, enquanto a outra parte serviu de controle para comparação. A determinação de qual parte receberia o PRP foi estabelecida por meio do lançamento de moeda, com "cara" sendo o lado direito ou proximal e "coroa" o lado esquerdo ou distal.

O grupo A serviu como controle e nele não havia nenhuma influência do PRP. O lado da ferida onde não foi utilizado o PRP no grupo B serviu como um controle mais fidedigno quanto às características da ferida, aspectos locais e gerais do paciente e cuidados pós-operatórios, diminuindo assim as possibilidades de vieses.

Na sala de recepção pré-operatória, foram colhidos $40 \mathrm{ml}$ do sangue venoso do paciente por meio de punção de veia periférica. $\mathrm{O}$ sangue foi colocado em 8 tubos esterilizados contendo $0,5 \mathrm{ml}$ de citrato de sódio a 3,2\% (BD Vacutainer), identificados e transportados para a sala de preparação do PRP em uma bolsa térmica. Utilizou-se o método de preparo de Vendramin et al. ${ }^{8}$, através de duas centrifugações, sendo a primeira com uma força de $400 \mathrm{~g}$ por dez minutos e a segunda $800 \mathrm{~g}$ também por dez minutos. Após a primeira centrifugação, utilizou-se uma seringa de $10 \mathrm{ml}$ e uma agulha Tuohy epidural ( $17 \mathrm{G}$ x $90 \mathrm{~mm}$ ) para retirada de toda a porção do plasma junto com a zona de névoa de cada um dos oito tubos e acondicionado em dois tubos, sem aditivos, esterilizados e com capacidade para $10 \mathrm{ml}$ (BD Vacutainer). Estes foram submetidos a segunda centrifugação, formando o botão plaquetário no fundo e o plasma pobre em plaquetas (PPP) na parte superior. Retirou-se com uma seringa de $10 \mathrm{ml}$ e a mesma agulha Tuohy epidural o excesso de PPP, deixando apenas uma quantidade de PPP referente a $10 \%$ do volume de sangue inicialmente retirado do paciente, ou seja, $2 \mathrm{ml}$ em cada um dos tubos de $10 \mathrm{ml}$. Agitou-os manualmente para dispersar as plaquetas e finalizar a preparação do PRP. Após a identificação, foram levados em bolsa térmica até a sala de cirurgia.

O PRP que se encontrava nos tubos foi aspirado em duas seringas de $3 \mathrm{ml}$ e permaneceu na mesa cirúrgica até o momento de sua aplicação, quando foi novamente agitado para dispersar as plaquetas e tornar o PRP mais homogêneo.

Foi administrada antibioticoprofilaxia com dois gramas de cefalotina após a venóclise, em todos os pacientes.

$\mathrm{O}$ procedimento de enxertia cutânea foi realizado da mesma forma em toda a ferida, com raspagem da parte mais superficial do tecido de granulação, sendo única diferença a utilização do PRP em uma das duas partes da ferida antes da 
fixação do enxerto de pele. Foram utilizados enxertos de pele de espessura parcial, retirados com dermátomos elétricos da marca Padgett ${ }^{\circledR}$.

$\mathrm{Na}$ cirurgia, a ferida foi marcada e dividida em duas áreas, sendo em uma utilizado o PRP e na outra não. A injeção foi feita em vários pontos o mais simétricos possível, distanciados cerca de $5 \mathrm{~mm}$ um do outro, com seringa de 3 $\mathrm{ml}$ e agulha $27 \mathrm{G}^{1} / 2$, em um plano correspondente à camada profunda do tecido de granulação, em torno de $5 \mathrm{~mm}$ de profundidade da superfície. Foi injetado $0,1 \mathrm{ml}$ de PRP em cada ponto e o número destes variou de acordo com a área da ferida (Figura 1). Após isto, fixou-se o enxerto de pele sobre a ferida (Figura 2).

A primeira troca de curativo foi feita cinco dias após a cirurgia e este segundo curativo permaneceu por mais três dias. A partir de então, as trocas ocorreram em dias alternados até a cicatrização. Os curativos foram feitos com solução fisiológica $0,9 \%$ e gaze com ácidos graxos essenciais (Dersani ${ }^{\circledR}$ ). A avaliação foi feita por meio de fotografias digitais com a câmera Sony W30. Estas fotografias foram realizadas no $14^{\circ}$ e $28^{\circ}$ dia de pós-operatório (DPO) com resolução de 3 megapixels, sendo colocada uma régua

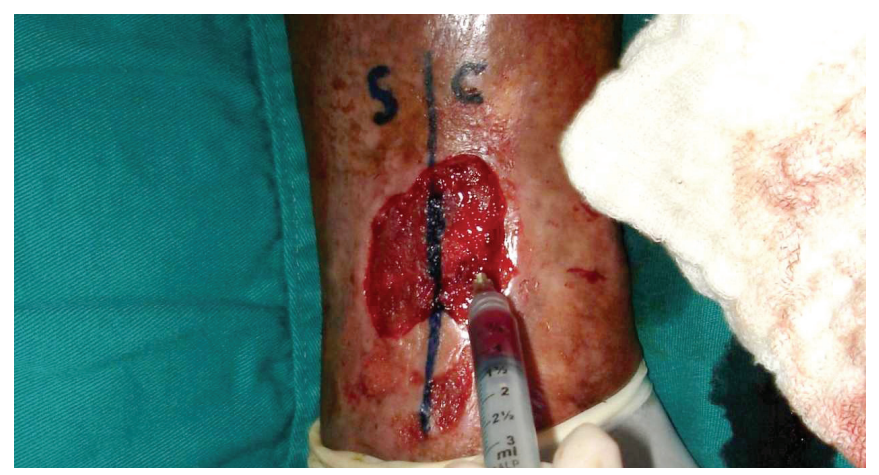

Figura 1 - Fotografia mostrando a ferida dividida em duas partes. O lado esquerdo será tratado sem o PRP e o direito onde ele está sendo injetado sob o tecido de granulação. Após isto, será colocado um enxerto de pele para o tratamento da ferida.

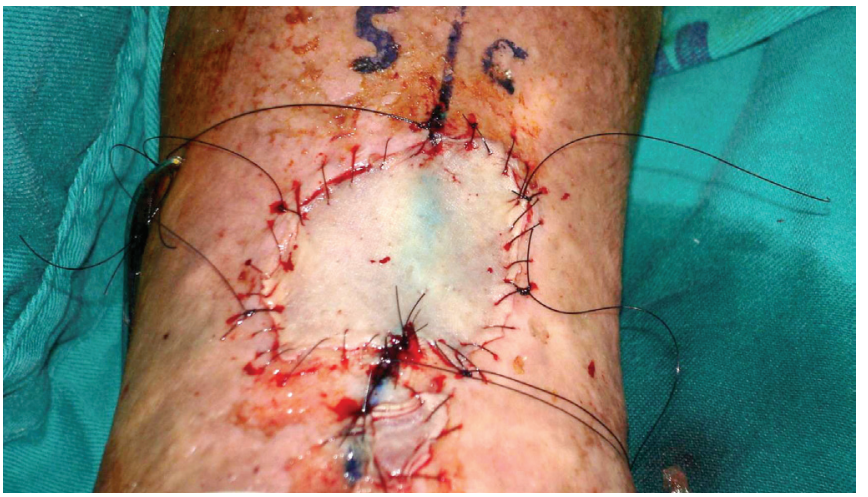

Figura 2 - Mesmo paciente da figura 1, ao final da cirurgia, como enxerto de pele de espessura parcial fixado sobre a ferida. ou uma marcação de $1 \mathrm{~cm}$ próxima à área do enxerto, para servir de referência para a avaliação computadorizada. As fotografias foram analisadas no programa Scion Image ${ }^{\circledR}$ por meio de medições das partes em que não houve integração do enxerto, tanto na área onde se utilizou o PRP quanto na área em que ele não foi utilizado. Estas avaliações foram realizadas por uma pessoa treinada e que desconhecia em qual dos lados havia sido aplicado o PRP. Compararam-se estatisticamente os resultados entre os grupos A e B, assim como entre as áreas onde se utilizou, ou não, o PRP no grupo B, com relação aos seguintes aspectos: percentual de integração dos enxertos; evolução clínica do enxerto entre o $14^{\circ}$ e o $28^{\circ}$ DPO; e perda total do enxerto.

A comparação entre os grupos com relação à melhor integração dos enxertos foi feita pelo teste ANOVA KruskalWallis. A comparação com relação à incidência de evolução desfavorável (aumento da perda do enxerto) e ao número de perdas totais do enxerto foi realizada pelo teste binomial para duas proporções.

\section{RESULTADOS}

A utilização do PRP na forma líquida injetada em um dos lados da(s) ferida(s) de pacientes que receberam enxerto de pele demonstrou melhor integração do enxerto nestas áreas, tanto na avaliação do $14^{\circ}$ DPO quanto do $28^{\circ}$ DPO (Tabela 1 e Figura 3). A média da integração do enxerto no lado onde se utilizou o PRP foi de $88,99 \%$, no $14^{\circ} \mathrm{DPO}$, e de $89,81 \%$, no $28^{\circ}$ DPO. Já o lado onde não foi utilizado o PRP apresentou média de integração do enxerto de $78,22 \%$, no $14^{\circ} \mathrm{DPO}$, e de $76,83 \%$, no $28^{\circ} \mathrm{DPO}$. A análise estatística por meio do teste ANOVA Kruskal-Wallis (teste $\mathrm{H}$ ) evidenciou um p-valor de 0,0039 , no $14^{\circ} \mathrm{DPO}$, e de 0,0082 , no $28^{\circ} \mathrm{DPO}$, constatando-se que é estatisticamente significativa a melhor integração do enxerto nas áreas onde se utilizou o PRP.

Ao comparar os resultados da integração do enxerto na área onde se utilizou o PRP com o grupo controle, pelo método ANOVA Kruskal-Wallis, foi comprovada a melhor integração do enxerto na área onde o produto foi utilizado (Tabelas 1 e 2; Figura 3), com um p-valor de 0,0098, no $14^{\circ}$ DPO, e menor que 0,0001 , no $28^{\circ}$ DPO. Isto também foi observado quando comparamos o lado onde não se injetou o PRP, no paciente em que ele foi utilizado na área adjacente, com o grupo controle, mas em intensidade menor (p-valor de 0,7388 , no $14^{\circ} \mathrm{DPO}$, e 0,0084 , no $28^{\circ} \mathrm{DPO}$ ) (Tabelas 1 e 2; Figura 3).

O lado que recebeu o PRP evoluiu de forma mais favorável entre o $14^{\circ}$ e o $28^{\circ}$ DPO (Tabela 1; Figura 3), embora, aplicando o teste binomial para duas proporções, tenhamos encontrado um p-valor de 0,0972 utilizando variáveis categóricas de melhora ou piora. Porém, isto foi bastante significativo quando comparamos o lado onde se utilizou o PRP e o grupo controle ( $\mathrm{p}$-valor $=0,0004)$.

Quando se avaliou a incidência de perda total nos enxertos onde se utilizou o PRP e se comparou através do teste binomial 


\begin{tabular}{|c|c|c|c|c|}
\hline \multirow[t]{2}{*}{ Ferida } & \multicolumn{2}{|c|}{14 dias } & \multicolumn{2}{|c|}{28 dias } \\
\hline & $\begin{array}{l}\text { Lado SEM } \\
\text { PRP }\end{array}$ & $\begin{array}{l}\text { Lado COM } \\
\text { PRP }\end{array}$ & $\begin{array}{l}\text { Lado SEM } \\
\text { PRP }\end{array}$ & $\begin{array}{c}\text { Lado COM } \\
\text { PRP }\end{array}$ \\
\hline 1 & $82,43 \%$ & $88,13 \%$ & $77,6 \%$ & $84,1 \%$ \\
\hline 2 & $91,94 \%$ & $91,11 \%$ & $86,81 \%$ & $67,86 \%$ \\
\hline 3 & $91,26 \%$ & $99,16 \%$ & $75,39 \%$ & $100 \%$ \\
\hline 4 & $67,46 \%$ & $87,49 \%$ & $69,58 \%$ & $87,96 \%$ \\
\hline 5 & $49,19 \%$ & $53,37 \%$ & $57,76 \%$ & $71,35 \%$ \\
\hline 6 & $78,66 \%$ & $90,42 \%$ & $98,33 \%$ & $100 \%$ \\
\hline 7 & $32,8 \%$ & $81,06 \%$ & $46,97 \%$ & $100 \%$ \\
\hline 8 & $63,89 \%$ & $93,62 \%$ & $82,5 \%$ & $100 \%$ \\
\hline 9 & $87,7 \%$ & $96,8 \%$ & $100 \%$ & $100 \%$ \\
\hline 10 & $52,63 \%$ & $41,28 \%$ & $100 \%$ & $80,85 \%$ \\
\hline 11 & $100 \%$ & $100 \%$ & $100 \%$ & $100 \%$ \\
\hline 12 & $76,2 \%$ & $93,18 \%$ & $70,62 \%$ & $91,8 \%$ \\
\hline 13 & $58,36 \%$ & $69,7 \%$ & $47,8 \%$ & $65,12 \%$ \\
\hline 14 & $82,9 \%$ & $95,06 \%$ & $89,27 \%$ & $100 \%$ \\
\hline 15 & $90,3 \%$ & $100 \%$ & $100 \%$ & $100 \%$ \\
\hline 16 & $71,56 \%$ & $82,3 \%$ & $46,13 \%$ & $63,24 \%$ \\
\hline 17 & $100 \%$ & $100 \%$ & $100 \%$ & $100 \%$ \\
\hline 18 & $60,03 \%$ & $91,8 \%$ & $15,4 \%$ & $100 \%$ \\
\hline 19 & $92,01 \%$ & $100 \%$ & $86,18 \%$ & $100 \%$ \\
\hline 20 & $47,7 \%$ & $68,93 \%$ & $18,35 \%$ & $39,68 \%$ \\
\hline 21 & $86,51 \%$ & $100 \%$ & $93,4 \%$ & $100 \%$ \\
\hline 22 & $84,27 \%$ & $92,15 \%$ & $94,32 \%$ & $100 \%$ \\
\hline 23 & $96,2 \%$ & $97,84 \%$ & $93,81 \%$ & $95,78 \%$ \\
\hline 24 & $90,18 \%$ & $100 \%$ & $76,7 \%$ & $100 \%$ \\
\hline 25 & $62,41 \%$ & $73,18 \%$ & $51,72 \%$ & $70,85 \%$ \\
\hline 26 & Perda total & Perda total & - & - \\
\hline 27 & $88,36 \%$ & $93,21 \%$ & $92,66 \%$ & $98,19 \%$ \\
\hline 28 & $100 \%$ & $100 \%$ & $93,81 \%$ & $92,13 \%$ \\
\hline 29 & $80,29 \%$ & $100 \%$ & $68,73 \%$ & $100 \%$ \\
\hline 30 & $100 \%$ & $100 \%$ & $98,10 \%$ & $98,96 \%$ \\
\hline 31 & $81,23 \%$ & $90,15 \%$ & $72,96 \%$ & $86,3 \%$ \\
\hline
\end{tabular}

para duas proporções com o grupo controle, observou-se menor incidência no grupo que utilizou o produto $(\mathrm{p}$-valor $=0,049)$.

\section{DISCUSSÃO}

O PRP é um produto retirado do sangue do próprio paciente, sendo, portanto, autólogo e por isto não apresenta riscos biológicos no que se refere à transmissão de doenças infectocontagiosas, como a hepatite, a síndrome da

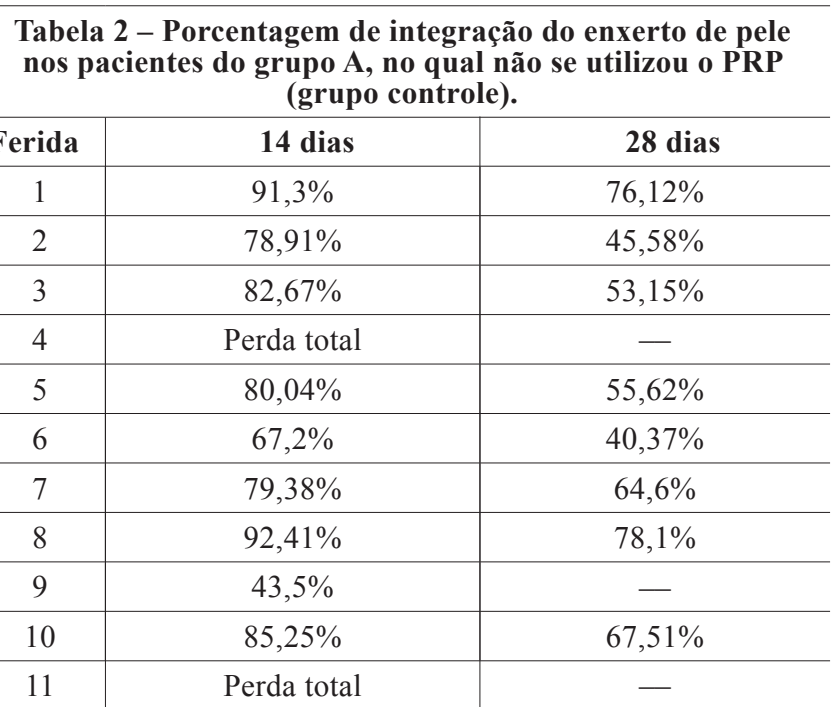

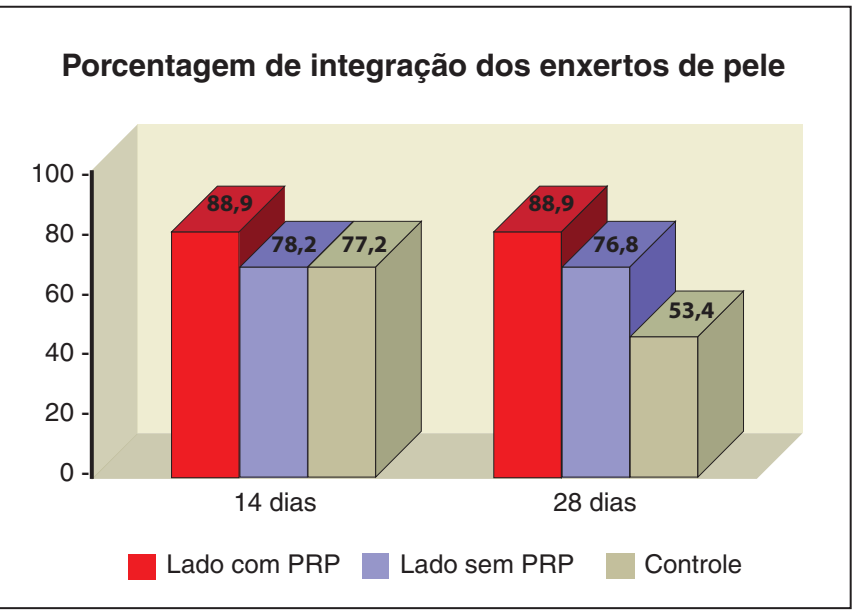

Figura 3 - Gráfico do porcentual de integração do enxerto de pele e sua evolução nos diferentes grupos, evidenciando melhor integração e evolução nas áreas onde foi utilizado o PRP.

imunodeficiência adquirida (AIDS), etc ${ }^{9-12}$. Porém, devem ser tomados todos os cuidados de assepsia no manuseio do sangue durante a preparação e a utilização do PRP para que não ocorra contaminação externa (patógenos do meio externo). Ele não é tóxico nem imunorreativo ${ }^{12} \mathrm{e}$ é utilizado logo após sua preparação, não sendo armazenado, congelado ou adicionados conservantes.

Enfatizamos a importância de treinamento prévio da técnica de obtenção do PRP, pois se mal preparado prejudicará a qualidade do produto, não alcançando o efeito desejado. Isto pode justificar muitas críticas quanto à eficácia do PRP.

Nos casos em que se espera um bom resultado, seja com ou sem o PRP, é óbvio que as diferenças serão poucas. Por isto escolhemos sua aplicação em feridas crônicas, onde 
geralmente ocorre perda dos enxertos de pele e então seria possível observar melhor a real atuação do PRP.

O processo de cicatrização dos enxertos de pele depende de vários fatores: qualidade do tecido de granulação, vascularização da área receptora, imobilização do enxerto e eficiência dos mecanismos de reparo ${ }^{13-15}$. A qualidade do tecido de granulação pode ser melhorada com o uso do PRP, porém a imobilidade é muito mais dependente dos cuidados pós-operatórios do paciente. A vascularização está relacionada ao estado da circulação local, que pode estar alterado devido a insuficiências vasculares, sejam elas venosas ou arteriais. Até a localização da ferida pode influenciar o resultado, porque algumas podem estar em regiões passíveis de compressão (apoio), como nas regiões posteriores ou laterais das pernas ou próximo à área de flexão (tornozelo). Então, é evidente a possibilidade de variações dos resultados em se tratando de pacientes diferentes, principalmente quando estudamos cicatrização, que é um evento multifatorial. Por isso, decidiu-se pela utilização do PRP na mesma ferida, que foi dividida em duas partes, sendo o PRP utilizado em uma parte e, na outra, não. Dessa forma, o controle foi parte da mesma ferida, no mesmo paciente, sendo mais fidedigno para comparação. Também utilizamos um outro grupo de pacientes cujas feridas foram tratadas com enxerto de pele sem o uso do PRP. Este outro grupo foi estudado para se evitar vieses, pois existiria a possibilidade do PRP estar influenciando a cicatrização do enxerto no lado da ferida sem o produto, devido à proximidade das áreas, o que acabou se comprovando ao analisarmos os resultados.

A utilização do PRP na forma líquida, injetado sob a ferida, facilitou sua preparação, uma vez que não foi necessário produzir a trombina. Também facilitou a maneira de administração, dispensando adaptadores na extremidade da seringa para misturar e borrifar o PRP com a trombina e assim formar o gel, como é habitualmente feito nas cirurgias. A injeção de $0,1 \mathrm{ml}$ de PRP feita em vários pontos o mais simétricos possível, distanciados cerca de $5 \mathrm{~mm}$ um do outro, em um plano correspondente à camada profunda do tecido de granulação, permitiu melhor controle da distribuição do produto (Figura 1)

A parte da ferida onde utilizamos o PRP teve melhor integração do enxerto de pele (Figuras 4 a 6). Nestas partes, a integração foi, em média, de $89 \%$ na avaliação no $14^{\circ} \mathrm{DPO}$
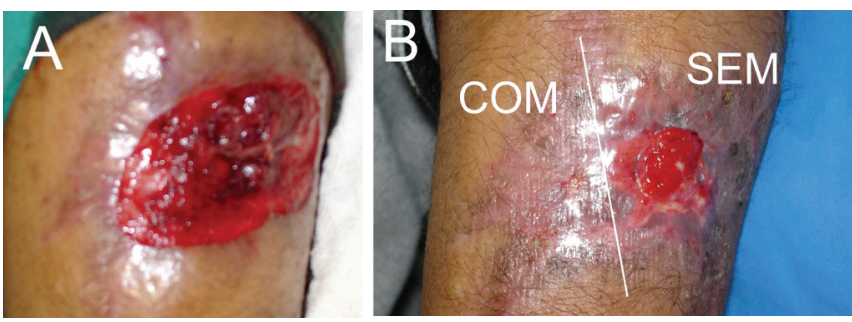

Figura 4 - A: Ferida a ser tratada com enxerto de pele e injeção de PRP no lado esquerdo. B: Pós-operatório. Houve boa integração do enxerto na área onde se utilizou o PRP e má integração na parte onde não se utilizou o produto.
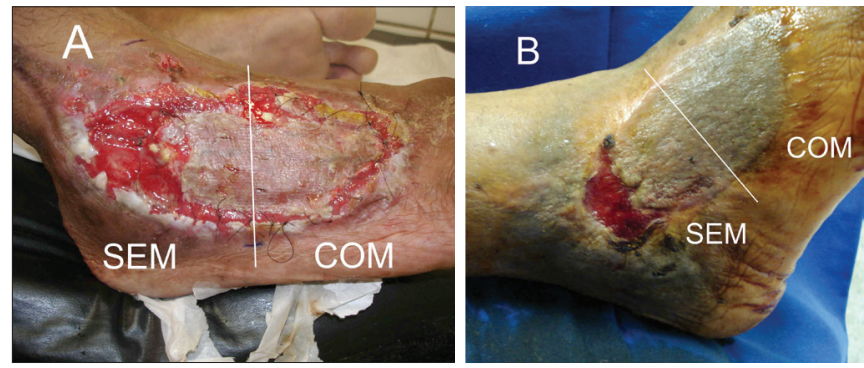

Figura 5-A: 14 dias de pós-operatório. Melhor integração do enxerto no lado que utilizou o PRP. B: 28 dias de pós-operatório. Integração total do enxerto de pele no lado que utilizou o PRP e perda de aproximadamente metade do enxerto no lado sem produto.


Figura 6-A: 14 dias de pós-operatório. Melhor integração do enxerto na parte inferior, que utilizou PRP. B: 28 dias de pósoperatório. Lado que utilizou o PRP totalmente cicatrizado e lado onde ele não foi aplicado apresentando áreas cruentas.

e de $89,81 \%$ no $28^{\circ}$ DPO. Já na parte das feridas onde não foi utilizado o PRP, a integração foi de $78,22 \%$, no $14^{\circ} \mathrm{DPO}$, e $76,83 \%$, no $28^{\circ} \mathrm{DPO}$. Isto foi bastante significativo com um p-valor de 0,0039 para o $14^{\circ} \mathrm{DPO}$ e de 0,0082 para o $28^{\circ} \mathrm{DPO}$, pelo teste ANOVA Kruskal-Wallis. O estudo também indicou que esta diferença pode ser ainda maior quando comparamos com o grupo de pacientes que não utilizaram o PRP (grupo $\mathrm{B})$. Isto mostra que a aplicação do produto próxima à área de enxerto já consegue trazer alguns benefícios. A integração do enxerto no grupo de pacientes que não utilizou o PRP foi a menor entre os grupos, sendo de $77,85 \%$, no $14^{\circ} \mathrm{DPO}$, e de $53,45 \%$, no $28^{\circ}$ DPO. Olhando-se por um outro lado, podemos dizer que no $28^{\circ} \mathrm{DPO}$ o percentual de perda parcial do enxerto no grupo que não utilizou o PRP foi de 46,55\%, enquanto que no grupo que utilizou o PRP esta perda, na parte da ferida em que ele não foi aplicado, diminuiu para $23,17 \%$, diminuindo ainda mais, para $10,19 \%$, na parte da ferida em que ele foi injetado. A diferença encontrada neste trabalho foi aproximadamente $36 \%$, em média, de maior área de integração do enxerto quando se utiliza o PRP. Em alguns dos casos, a melhora foi excelente, com a integração total do enxerto no lado com PRP, embora houvesse uma extensa perda no lado sem o produto. Porém, tivemos casos nos quais a integração foi boa em ambos os lados e casos em que ela não foi boa nem mesmo no lado com PRP. 
Outro aspecto importante é que, nos pacientes que utilizaram o PRP, a evolução do enxerto foi melhor ( $\mathrm{p}$-valor $=0,0004$; teste binomial para duas proporções). Em feridas crônicas e com problemas de circulação, é comum observarmos a perda gradual do enxerto, que inicialmente parecia ter integrado satisfatoriamente. Isto é bem evidente no grupo de pacientes no qual o PRP não foi utilizado. Neste grupo houve perda de $24,4 \%$ do enxerto, em média, ao comparar a evolução do $14^{\circ}$ para o $28^{\circ}$ DPO. No grupo de pacientes que utilizaram o PRP, a parte da ferida onde foi aplicado o produto manteve o resultado (melhora de $0,82 \%$ ).

Nas feridas em que se utilizou o PRP, a incidência de perda total do enxerto foi significativamente menor $(3,22 \%)$ que naquelas onde ele não foi utilizado $(18,18 \%)$ (p-valor $=$ 0,049 ; teste binomial para duas proporções). Nestes casos foi feito o diagnóstico clínico de infecção, devido à presença de exsudado abundante e hiperemia na ferida.

O PRP mostrou-se eficiente e seguro e a técnica de obtenção apresentada nesse trabalho pode ser uma alternativa para implementar sua utilização em hospitais públicos, pois apresenta baixo custo. Porém, ele não deve ser utilizado como uma panaceia e sim como um produto adjuvante na cicatrização de feridas, indicado quando temos ou existe uma considerável chance de termos problemas na cicatrização ou na integração de enxertos.

\section{CONCLUSÃo}

O trabalho permitiu chegar às seguintes conclusões:

- PRP injetado sob a ferida melhora em $36 \%$, em média, a integração do enxerto de pele em pacientes com feridas crônicas;

- PRP injetado sob a ferida melhora a evolução dos enxertos de pele em pacientes com feridas crônicas, diminuindo $25 \%$, em média, a perda do enxerto entre o $14^{\circ}$ e o $28^{\circ}$ dias de pós-operatório.

\section{REFERÊNCIAS}

1. Cooper DM, Yu EZ, Hennessey P, Ko F, Robson MC. Determination of endogenous cytokines in chronic wounds. Ann Surg. 1994;219(6):68891.

2. Crovetti G, Martinelli G, Issi M, Barone M, Guizzardi M, Campanati B, et al. Platelet gel for healing cutaneous chronic wounds. Transfus Apher Sci. 2004;30(2):145-51.

3. Greenhalgh DG. Wound healing and diabetes mellitus. Clin Plast Surg. 2003;30(1):37-45.

4. Robson MC. The role of growth factors in the healing of chronic wounds. Wound Repair Regen. 1997;5(1):12-7.

5. Stadelmann WK, Digenis AG, Tobin GR. Physiology and healing dynamics of chronic cutaneous wounds. Am J Surg.1998;176(2A Suppl):26S-38S.

6. Vendramin FS, Franco D, Schamall RF, Franco TR. Utilização do plasma rico em plaquetas (PRP) autólogo em enxertos cutâneos em coelhos. Rev Bras Cir Plást. 2010;25(1):4-10.

7. Vendramin FS, Franco D, Nogueira CM, Pereira MS, Franco TR. Plasma rico em plaquetas e fatores de crescimento: técnica de obtenção e utilização em cirurgia plástica. Rev Col Bras Cir. 2006;33(1):24-8.

8. Vendramin FS, Franco D, Franco TR. Método de obtenção do gel de plasma rico em plaquetas autólogo. Rev Bras Cir Plást. 2009;24(2):2128.

9. Man D, Plosker H, Winland-Brown JE. The use of autologous plateletrich plasma (platelet gel) and autologous platelet-poor plasma (fibrin glue) in cosmetic surgery. Plast Reconstr Surg. 2001;107(1):229-37.

10. Marx RE, Carlson ER, Eichstaedt RM, Schimmele SR, Strauss JE, Georgeff KR. Platelet-rich plasm: growth factor enhancement for bone grafts. Oral Surg Oral Med Oral Pathol Oral Radiol Endod. 1998;85(6):638-46.

11. Marx RE. Platelet-rich plasm: evidence to support its use. J Oral Maxillofac Surg. 2004;62(4):489-96.

12. Pacifici L, Casella F, Maggiore C. Plasma arricchito di piastrine (PRP): metodi di estrazione e potenzialità d'uso. Minerva Stomatol. 2002;51(78):341-50.

13. Dockhorn LF, Zanini SA, Mélega JM. Enxertos de pele. In: Mélega JM, Zanini SA, Psillakis JM, eds. Cirurgia plástica reparadora e estética. Rio de Janeiro:Medsi;1992. p.35-42.

14. Franco D, Claudio-da-Silva CS. Enxertos, retalhos e inclusões. In: Franco T, ed. Princípios de cirurgia plástica. Rio de Janeiro:Atheneu;2002. p.87-106.

15. Rudolph R, Ballantyne Jr DL. Skin grafts. In: McCarthy JG, ed. Plastic surgery. Philadelphia: W.B. Saunders;1990. p.221-74.
Correspondência para:
Fabiel S. Vendramin

Av. Generealíssimo Deodoro, 391 - Umarizal - Belém, PA, Brasil - CEP 66055-240

E-mail: fabiel@doctor.com 